\title{
Calculation method problems of KPSS P10
}

\author{
Ümit ÇELEN*
}

\begin{abstract}
KPSS Licensing exams are administered annually; the scores are valid for two years. For this reason, the equivalence of the examinations is important. This study has aimed at analyzing the calculation techniques. Certain problems have been found with the calculation. The comparison of the received scores between the previous year and the following year becomes risky as the overall points are calculated by applying a conversion to the grades which are reached after the group internal ranking of the individuals' standardized grades. The points obtained by this method are affected by the points of the highest scored candidate, by the performance of the individuals not taking any one of these tests, and by the degree of the heterogeneity and homogeneity within the scores of the examinees. In addition, the impact of two sub tests, general ability and general culture is more than the predicted; on the other hand the impact of sub test of the educational sciences is lower than the predicted in the P10 test scores. In the study, some suggestions were made in the light of these findings.
\end{abstract}

Keywords: KPSS, standard scores, score calculation.

* Assist. Prof. Dr., Eskişehir Osmangazi University, Faculty of Education, Department of Educational Science, Eskişehir, Turkey. E-mail: umitcelen@yahoo.com 


\section{SUMMARY}

Purpose and Significance: The aim of this study was to examine the calculation technique of the KPSSP10 scores that is used to determine the appointments of the teachers. With the help of the findings, it is intended to identify the potential problems which may arise due to the calculation technique of the scores which are valid for two years and some solutions to these problems are suggested.

Method: The data used in the study were obtained from the OSYM (National Center for the Selection and Placement Centre) web page. They published all of the parameters of KPSS 2010. For previous examinations, unknown parameters have been predicted. In the sections in which the changes of the parameters used in the calculation of P10 were examined, the parameters were kept constant except for the parameter whose change was under examination.

Results: In KPSS exam for teachers, candidates answer three separate tests: "General Ability" (GY), "General Culture" (GK) and the "Educational Sciences" (EB). The three test scores are then transformed into standard scores (ASP). These scores are converted into KPSSP10 scores using a formula. The value of the highest APS (B) used in the calculation of the KPSS 2010 -whether high or low- has an effect on the slope of the line formed between ASP and P10. If the B score is very high, the scores of the candidates, who scored $0.5 * \mathrm{~S}$ more than the average score, decrease while the grades of the candidates, who scores less than the average, increase. When the B is too low, the opposite situation happens. Value changes in the average ASP (X) and standard deviation (S) used in the calculation of P10 affects the distribution of the scores. Low $\mathrm{X}$ and low $\mathrm{S}$ cause an increase in the scores of all candidates except the candidates having the highest ASP scores. While calculating KPSS scores, despite the conversion process, each correct answer has a certain amount of computable contribution to the P10 scores. One more correct answer in the GY test causes the highest increase in the overall test scores. This condition has been valid for the last six exams. When the average contributions of the tests are investigated, it is observed that $1 \mathrm{GY}$ article causes 0.500 points, $1 \mathrm{GK}$ article 0.453 points and $1 \mathrm{~EB}$ article 0.333 points of increase.

Discussion: The findings of the study demonstrate that the value of the highest ASP (B) -whether high or low- influences the calculated points. Considering the fact that the results are valid for two years, it is clear that the 
situation creates inequality. Both the average of the distribution of ASP points and standard deviation has had an effect on calculated scores. While the in-group rank of a candidate remains constant, it corresponds to a higher score in a year when the $\mathrm{X}$ and $\mathrm{S}$ are low. On the other hand, the same rank brings lower scores if the $\mathrm{X}$ and $\mathrm{S}$ are high in that year. If GY and GK test scores are calculated only by EB test holders then distribution of ASP average will be 50 and the standard deviation will be 10; but if the T points of the two tests are calculated for all KPSS licensing candidates, these values will be different. Therefore performance of all the candidates (including the candidates other then teachers) applied for the exam has an effect on candidate teachers' scores. Moreover this impact becomes clearer as it causes an overall increase in the scores, especially when the successes of the teaching profession candidates are relatively low. Similarly, if the candidates who applied for teaching profession get similar points and become a homogeneous group, this situation causes a fall in their scores. With the current calculation method, the share impact of the each test in P10 is far from the predicted one. When the last six exams were tested, the findings show that the most important determinant test is the GY test in the selection of teacher candidates. In these examinations, teacher candidates who have received a training that does not require verbal skills are expected to answer verbal proficiency questions while the candidates who have received a training that does not require numerical skills are expected to answer numerical proficiency questions.

Conclusions: The obtained P10 scores from the KPSS Licensing exams are valid for two years. For this reason, maximum attention should be devoted to the comparability of the two exams that are held in different years with different questions and with the participation of different candidates. In this regard, the current method of calculation points has a structure that could lead to inequalities. The examination results may be affected by various conditions such as the performances of the all candidates whose P10 is calculated. Moreover, the results vary annually in relation to the performance of the candidate who scored highest in the exam and also in relation to performances of the other public employee candidates who did not even answer to EB test. In addition, the scores of the teacher candidates, who answer three different tests, are most affected by the GY test while they are least affected by the EB test, which should actually be having the strongest impact. 


\title{
KPSS P10 Hesaplama Yöntemine İlişkin Sorunlar
}

\author{
Ümit ÇELEN *
}

ÖZ. KPSS Lisans sınavları her yıl yapılmakta, puanları ise iki yıl geçerli olmaktadır. Bu nedenle yapılan sınavların denkliği önemlidir. KPSSP10 puanlarının hesaplanma yönteminin incelenmesinin amaçlandığ 1 bu çalışmada, ilgili puanın hesaplanma yöntemine ilişkin bazı sorunlar tespit edilmiştir. Standart puanlara çevrilerek bireylerin grup içerisindeki sıralamasına göre elde edilen puanların, kullanılan formülle P10 puanlarına dönüştürme işlemi sonucunda bir önceki ve bir sonraki yıl puanlarıyla karşılaştırılabilirliği tehlikeye girmektedir. $\mathrm{Bu}$ yöntemle puanlar, en yüksek performansa sahip adayın puanından, bu testlerden birini almayan diğer bireylerin performansından ve puanların homojenliği veya heterojenliğinden etkilenir hale gelmektedir. Ayrıca P10 puanları içerisinde genel yetenek ve genel kültür alt testinin payı öngörülenden çok, eğitim bilimleri testinin ise azdır. Çalışmada bu bulgular ışı̆̆ında bazı önerilerde bulunulmuştur.

Anahtar Sözcükler: KPSS, standart puanlar, puan hesaplama.

*Yrd. Doç. Dr., Eskişehir Osmangazi Üniversitesi Eğitim Fakültesi Eğitim Bilimleri Bölümü Eskişehir, Türkiye. E-posta: umitcelen@yahoo.com 


\section{GÍRIŞ}

1739 sayılı ve 1972 tarihli Milli Eğitim Temel Kanunu'na göre "öğretmenlik, Devletin eğitim, öğretim ve bununla ilgili yönetim görevlerini üzerine alan özel bir ihtisas mesleğidir" (MEB, 2010). Bu mesleğe yönelik insangücü yetiştirme faaliyetlerini 1848 y1lında İstanbul'da kurulan Darülmuallimin adındaki öğretmen okuluyla başlatmak mümkündür (Akyüz, 2005). O tarihten günümüze kadar da hem öğretmen yetiştirilmesi, hem de istihdamıyla ilgili pek çok değişik yöntem izlenmiştir.

Günümüzde Milli Eğitim Bakanlığı'na bağlı kurumlara öğretmen atamaları, 2003 yılından bu yana ÖSYM (Ölçme Seçme ve Yerleştirme Merkezi) tarafından yapılan KPSS (Kamu Personeli Seçme Sınavı) puanlarıyla yapılmaktadır. Adaylara, KPSS kapsamında Genel Kültür (GK), Genel Yetenek (GY) ve Eğitim Bilimleri (EB) testleri uygulanmaktadır. 2010 yılında yapılan KPSS Lisans Eğitim Bilimleri sınavına yaklaşık 290 bin aday başvurmuştur. Milli Eğitim Bakanlığı'nın (MEB) 2010 yılı içerisinde, bu sınavın puanları kullanılarak atamasını yapacağı kadrolu öğretmen sayıs1 30.000'dir. Bazı branşlarda öğretmen ataması daha fazla, bazılarında ise çok az yapıldığından branşlara göre değişiklik göstermekle birlikte, sınava girmek için başvuran öğretmen adaylarının yaklaşık 10'da 1'inin atanabileceği görülebilir. Atanma oranının bu denli düşük olması, sinavın önemini artırmaktadır.

Öğretmen atamalarında kullanılan KPSS P10 puanının geçerliliği 2 y1ldır. Öğretmen adayları sınava ait puanı o yıl ve ondan sonraki y1l atamalarında kullanabilmekte ve hangi puanı yüksek ise o puanla atanabilmektedir. Bu durum her yıl yapılan sınavın denkliğinin sağlanması gerekliliğini doğurmaktadır. Test geliştiricilerin veya kurumların tamamıyla birbirine paralel, fakat farklı sorulardan oluşan ve testi alan her bir birey için aynı veya benzer sonuçlar üreten testler yapılandırmaları oldukça zordur ve beklenemez (Kan, 2010). Bunun yerine, farklı test formlarından elde edilen puanların birbiriyle karşılaştırılabilir hale getirilebilmesi için geliştirilen "test eşitleme" yöntemleri söz konusudur (Crocker ve Algina, 1986). ÖSYM'nin her yıl yaptığı ancak puanları iki yıl geçerli olan KPSS'de uygulanan testleri eşitleyerek puanları karşılaştırılabilir hale getirmeye yönelik bir çalışma yapmadığı bilinmektedir. Bu sınavların geliştirilmesinde esas alınan kuram olan klasik test kuramının bir sinırlılığı olan, "elde edilen tüm test ve madde istatistiklerinin testin uygulandığı gruptan etkilenmesi" gerçeği, farklı kişilerle yapılan ve değişik maddelerden oluşan bir sınavın puanının diğer bir sınavdan alınan puanla aynı gibi düşünülmesini mümkün kılmamaktadır. Karşılaştırma için kullanılan, en bilinen yol puanları ortalamanın ve standart sapmanın etkisinden kurtararak standardize etmektir (Tekin, 1996; Turgut ve 
Baykul, 2010). Test puanlarının standardizasyonu, her puanın grup ortalamasından çıkarılıp, grubun standart sapmasına bölünmesiyle bulunan Z dönüşümü ile yapılmaktadır. Böylelikle her puan, grubun aritmetik ortalamasına olan uzaklığına göre bir $\mathrm{Z}$ değeri almaktadır. $\mathrm{Z}$ değerini, bir sınav sonucu olarak açıklanmasına alışık olunmayan -1.26; 2.33 gibi değerlerden kurtarmak için de Z değerinin 10 ile çarpılıp 50'ye eklenmesiyle bulunan $T$ puanlarına dönüştürmek, yine sıkça başvurulan bir yoldur.

KPSSP10 puanlarının standardizasyonunda, öncelikle her üç test kendi içinde değerlendirmeye tabi tutulmaktadır. Her test için adayların yanlış sayılarının dörtte birinin doğru sayılarından çıkartılmasıyla elde edilen net sayıları bulunmakta ve buna dayalı olarak standart puanlar hesaplanmaktadır. Elde edilen GY ve GK standart puanları 0.3; EB standart puanı ise 0.4 katsayısıyla çarpılmakta, bunların toplamından ağırlıklı standart puan (ASP) elde edilmektedir. Bu işlemlerin sonucunda aşağıdaki formül kullanılarak her adayın KPSS puanı hesaplanmaktadır (ÖSYM, 2010a: 16).

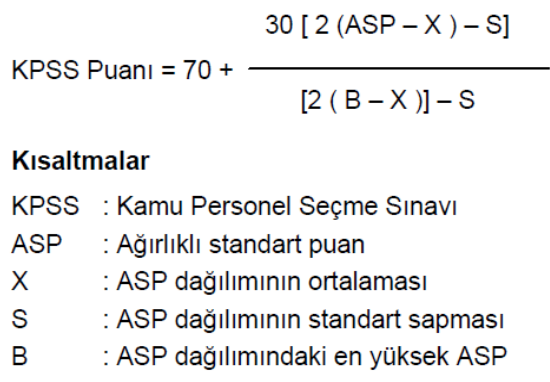

Her yıl T puanlarına çevirerek standardize edilen KPSS puanlarının, her ne kadar farklı bir gruptan ve farklı sorularla elde edilmiş olsa bile, sınava girilen yıldaki grup içindeki konuma göre diğer bir deyişle sınavdaki sıralamaya göre eşitlenmiş olduğu varsayılabilir. Ancak, halen kullanılan KPSS puan hesaplama formülünde, bu standardizasyonun dişında başka bir işlem daha yapılmaktadır. GY, GK ve EB testlerinden elde edilen T puanları, sırasıyla $0.3 ; 0.3$ ve 0.4 katsayılarıyla çarpılmakta, bu üçünün toplamından elde edilen ağırlıklı standart puanın (ASP) ortalaması ve standart sapması bulunmaktadır. Formülde ayrıca en yüksek ASP'ye sahip adayın puanı kullanılmaktadır. $\mathrm{Bu}$ durumda, en yüksek ASP'li adayın puanı 100; ortalamadan 0.5 standart sapma yüksek adayın puanı ise 70 olmaktadır. Bu iki puan dışındaki adayların puanları o yıl hesaplanan diğer istatistiklerden etkilenmektedir.

10-11 Temmuz 2010'da yapılan KPSS'de EB testi, "sınav sürecinde bazı usulsüzlüklerin meydana geldiği kanaatine varıldığından, telafisi 
mümkün olmayan zararların ortaya çıkmasını engellemek için iptal edilmiştir" (ÖSYM, 2010b). İptal edilen Temmuz 2010 EB sınavının yerine yapılan Ekim 2010 sinavı sonrasında adaylar EB testi netlerine göre puanlarında bir artış veya düşüş olacağı beklentisine girmişlerdir. GY ve GK testleri iptal edilmediğinden, EB netlerini iptal edilen sınava göre artıran adayların böyle bir beklenti içine girmesi normal karşılanabilir. Ancak puanların açıklanmasıyla birlikte, bu beklentisi karşılanmayan pek çok aday puanlarının yanlış hesaplandığı iddiasını dile getirmiştir. Basında da yer alan bu itirazlara ÖSYM'nin cevabı ise şöyle olmuştur (ÖSYM, 2010c):

"Her sinav kendi içinde standardize edildiğinden, ortalamanın yükselmesi aynı netlerle puanın düşmesi sonucunu doğurur. Ancak, tüm kitle kendi içinde standardize edilerek puan hesaplanmaktadır. Bu yüzden, herhangi bir haksızlık söz konusu değildir."

ÖSYM'nin yapmış olduğu bu açıklama, itirazların sona ermesi için yeterli gelmemiş olmalıdır ki, benzer bir açıklama bir kez daha yapılmak zorunda kalınmıştır (ÖSYM, 2010d). ÖSYM ayrıca puan hesaplamasında kullandığı formülü tekrar hatırlatmış, daha önceki sınavlarda hiç açıklamamış olduğu ASP'lere ilişkin $\mathrm{X}, \mathrm{S}$ ve $\mathrm{B}$ değerlerini açıklamıştır. Ayrıca bir aday için örnek puan hesaplamasına da yer verilmiş, böylelikle puan hesaplama yöntemiyle ilgili şüpheleri gidermeye çalışmıştır.

Ancak asıl itiraz konusu olan durum, GY ve GK puanlarında değişme olmayacağına göre, tekrar edilen sınavda aynı T puanını alan, yani grup ortalamasından aynı uzaklıkta olan bir adayın puanının değişmiş olmasıdır. Adayların sınav sonuçları incelendiğinde, iptal edilen sınava göre grup içindeki sırası gerilemesine rağmen puanı artan veya sıralamada 20 bin kişiyi daha geçmesine rağmen puanı azalan adaylar olduğu görülmektedir. $\mathrm{Bu}$ nedenle, puan hesabında kullanılan her bir parametrenin değişiminin puanlar üzerinde nasıl bir etki oluşturacağının incelenmesinin gerekli olduğu düşünülmüştür.

$\mathrm{Bu}$ çalışmada öğretmen olarak atanacakların belirlenmesinde kullanılan KPSSP10 puanlarının hesaplanma yönteminin incelenmesi amaçlanmıştır. İnceleme sonucunda iki yıl kullanılan bu puanların hesaplanmasıyla ilgili oluşabilecek sorunları belirlemek ve tespit edilen sorunlara ilişkin çözüm önerileri üretmek hedeflenmiştir.

\section{YÖNTEM}

Araştırmada kullanılan veriler, ÖSYM tarafindan açıklanan veriler olup kurumun internet sitesinden elde edilmiştir. $\mathrm{Bu}$ veriler kullanılırken bir kısıtlılık söz konusudur çünkü ÖSYM yaptığı sınavlarla ilgili tüm verileri 
açıklamamaktadır. Örneğin testlerin aritmetik ortalama ve standart sapmalarını açıklamaktadır ancak en yüksek net sayısına sahip adayın kaç neti olduğu bilgisi bu açıklama içerisinde yer almamaktadır. Sınavdan yaklaşık iki yıl sonra yayımlanan sonuç kitaplarında ham puan dağılımları görülebilmektedir fakat bu bilgi ile GY, GK ve EB testlerinden aldığ 1 puanlarla en yüksek ASP'ye sahip adayın puanına, ASP ortalamasına ve standart sapmasına ulaşmak mümkün olmamaktadır. İstisna olarak yenilenen KPSS 2010 sınavına ilişkin puan hesabında kullanılacak tüm veriler açıklanmıştır. Bu çalışmada 2010 tekrar sınavına ilişkin açıklanan verilerden yararlanılmıştır. P10 hesaplamasında kullanılan parametrelerin değişimlerinin incelendiği bölümlerde, değişimi incelenen parametre dışındaki parametreler sabit tutulmuştur. Diğer değerler, 2010 sınavında gerçekleşen, ASP puan dağılımının ortalaması $X=51.801$; standart sapması $\mathrm{S}=8.129$; en yüksek ASP'li adayın puanı $\mathrm{B}=70.102$ olarak alınmıştır.

Testlerdeki 1 doğru artışının P10'u nasıl artırdığına ilişkin hesaplamalar yapılırken, diğer alt testlerin doğru sayıları sabit tutulmuş, sadece ilgili alt testte bir doğru artırılmış, bu şekilde değişen ASP hesaplanmıştır. ASP'deki bu artışı X ve S üzerindeki etkisi ihmal edilmiştir. Bu ASP kullanılarak P10 formülünden elde edilen puanla bir doğru artırılmadan hesaplanan puanın farkı alınmış, bu farka "1 doğru artışıyla meydana gelecek artış" denilmiştir.

\section{BULGULAR}

P10 hesaplanmasında kullanılan formül incelendiğinde, en yüksek ASP'ye sahip adayın puanının 100 olacağı öngörülebilir. ASP puan dağılımı ortalamasından $0.5 * \mathrm{~S}$ yüksek puan almış olan adayın bu formülle hesaplanacak olan puanı 70'tir. Bu iki puan dışında hiçbir ASP'nin karşılığ P10, diğer parametreler bilinmeden bilinemez.

KPSS 2010 EB testinin, çok sayıda 120 doğrusu olan aday bulunması nedeniyle oluşan şüpheler üzerine iptal sürecine gittiği bilinmektedir. Yenilenen sınavda ise en yüksek EB netinin 111 olduğu açıklanmıştır. Bu durum akla sınav birincisinin daha az sayıda doğru yapmasının diğer adayların puanlarını etkileyip etkilemeyeceği sorusunu getirebilir. P10 hesaplanmasında kullanılan B'nin 70.102 olduğu açıklanmıştır. Bu sınava çok başarılı bir adayın katılmış ve tüm soruları doğru yanıtlamış olması durumunda ise B, 73.750 olacaktır. EB testinin birincisinin GY ve GK testlerinde çok iyi bir performans gösterememesi durumu söz konusu olduğunda ise bu puan düşecektir. En yüksek ASP'nin (B) değişiminin diğer adayların puanlarını nasıl etkilediğine ilişkin grafik Şekil 1'de sunulmuştur. 


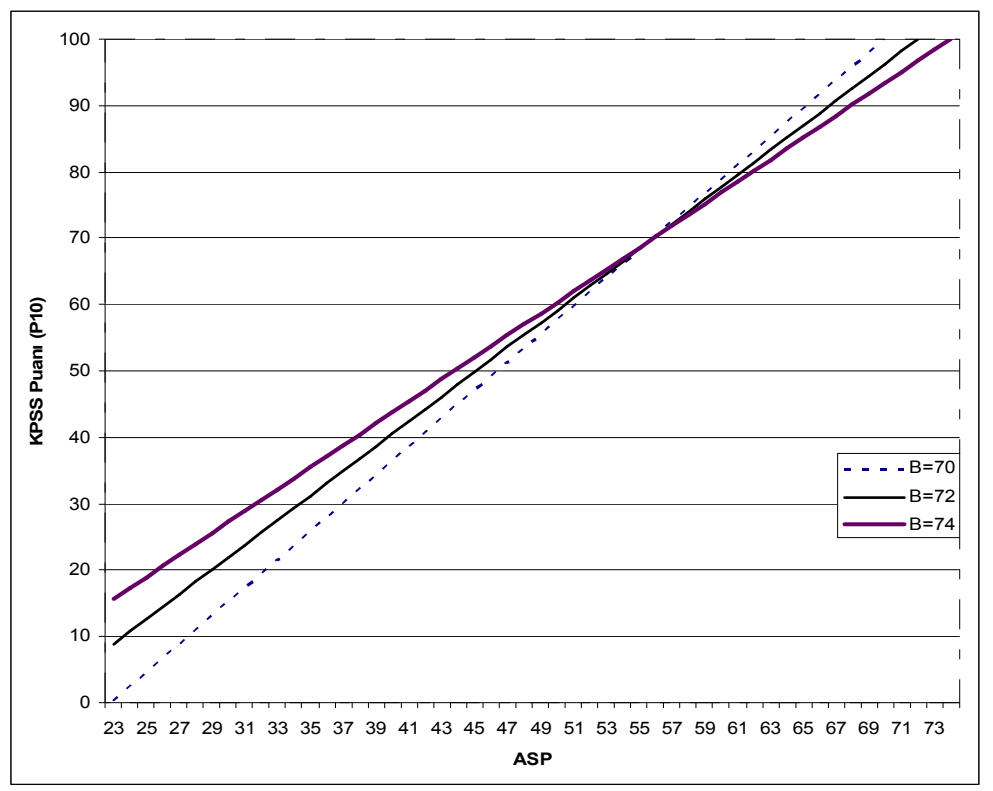

Şekil 1. "En yüksek ASP'nin” (B) değişimiyle puanlarda meydana gelen değişim

Grafikten de görüleceği gibi, B'nin düşük ya da yüksek olması, ASP ile P10 arasında oluşan doğrunun eğimini etkilemektedir. B yükseldiğinde, ASP'si ortalamadan $0.5^{*}$ S'den daha yüksek adayların puanı düşmekte, daha düşük olan adaylarınki ise artmaktadır. B düştüğünde ise tam tersi bir durum ortaya çıkmakta, ASP'si X+0.5*S'nin altında olan adayların P10 puanları düşmekte, diğer adaylarınki ise yükselmektedir.

P10 hesaplanmasinda kullanılan, ASP'lerin ortalama ve standart sapma değerlerindeki değişimler dağılımdaki puanları etkilemektedir. İlk bakışta bu gayet normal görülebilir, çünkü puanları standartlaştırırken grubun ortalaması ve standart sapması kullanılmaktadır. Ancak GY ve GK testlerinin standart puanlarının yaklaşık 800 bin kişiden hesaplanıyor olduğu göz ardı edilmemelidir. EB testi standart puana çevrilirken hesaplamaya katılan kişi sayısı bunun yaklaşık 3'te 1'i kadardır. Dolayısıyla formüldeki $\mathrm{X}$, EB testini alanların yanı sira bu testi yanıtlamayanların GY ve GK performanslarından da etkilenmektedir. Ortalama ve standart sapmadaki değişimin P10 puanlarını nasıl etkilediğine ilişkin grafikler Şekil 2 ve 3'te sunulmuştur. 


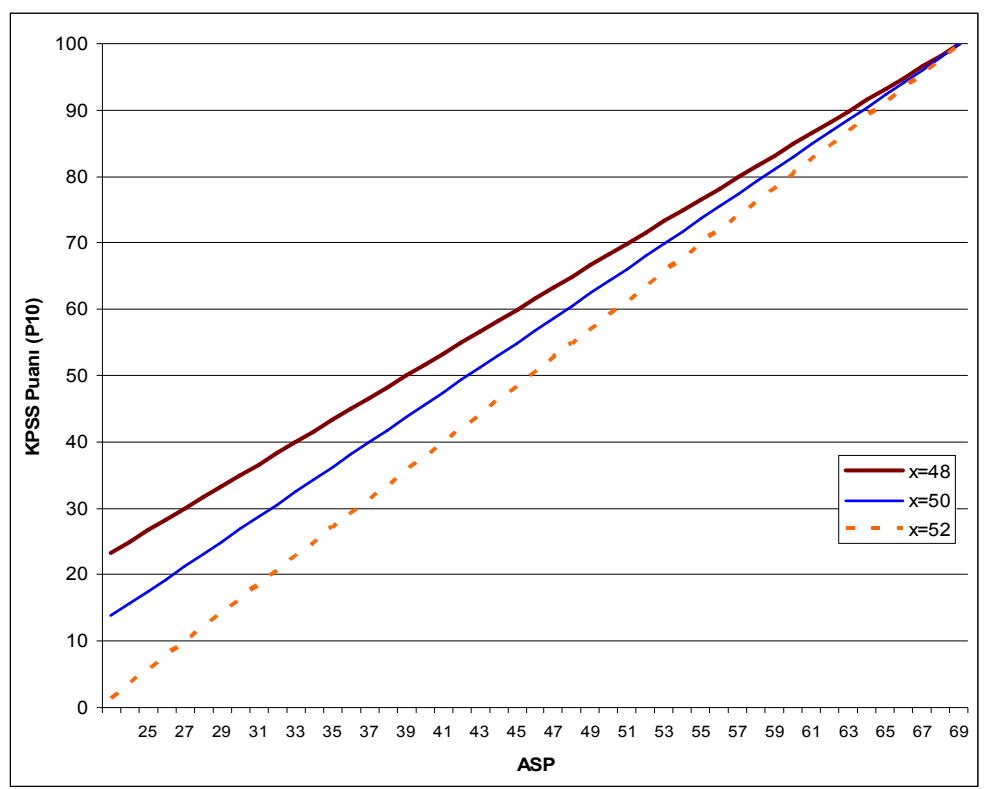

Şekil 2. ASP dağılımının ortalamasının $(X)$ değişimiyle puanlarda meydana gelen değişim

Şekil 2 ve 3'ten görüleceği gibi, düşük $X$ ve düşük $S$, en yüksek ASP'li aday dışındaki tüm adayların puanlarının artmasına neden olmaktadır. ASP puan dağılımının ortalamasının düşük çıkması, EB testini yanıtlayan adayların GY ve GK testini yanıtlayan adaylar arasında daha düşük performans göstermeleri sonucunda ortaya çıkabilir. Düşük S ise P10 puanı hesaplanan adayların ASP puanlarının daha homojen olması ile ortaya çıkabilir. Öğretmen adaylarının diğer kamu personeli adaylarına göre daha düşük GY ve GK performansı göstermeleri, o yıl hesaplanan puanların daha yüksek olmasına neden olmaktadır. Daha başarılı bir öğretmen adayı grubunun girdiği yılda ise P10'lar daha düşük olacaktır. Öğretmen adaylarının birbirlerine yakın performans göstermeleri puanlarının yüksek; daha heterojen puanlar almaları ise düşük olması sonucunu ortaya çıkaracaktır. Şekil 4'te, son sınavda ortaya çıkan X, S ve B değerlerinin sirasiyla 50,10 ve 74 olması durumunda puanlarda meydana gelecek değişim gösterilmektedir. Grafik incelendiğinde, bu değerlerin 50, 10 ve 74 olması yerine $51.801,8.129$ ve 70.102 olmasının, yüksek puanları artırdığı; düşük puanları ise daha fazla düşürdüğü bulgusuna ulaşılmaktadır. 


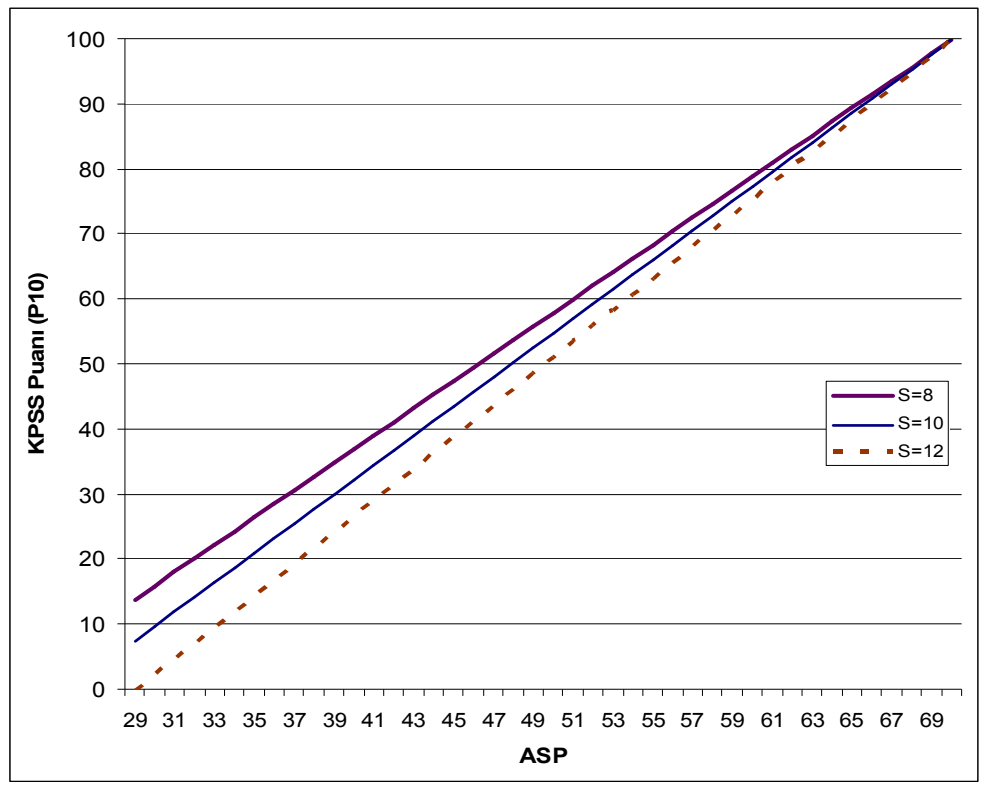

Şekil 3. ASP dă̆ılımının standart sapmasının (S) değişimiyle puanlarda meydana gelen değişim

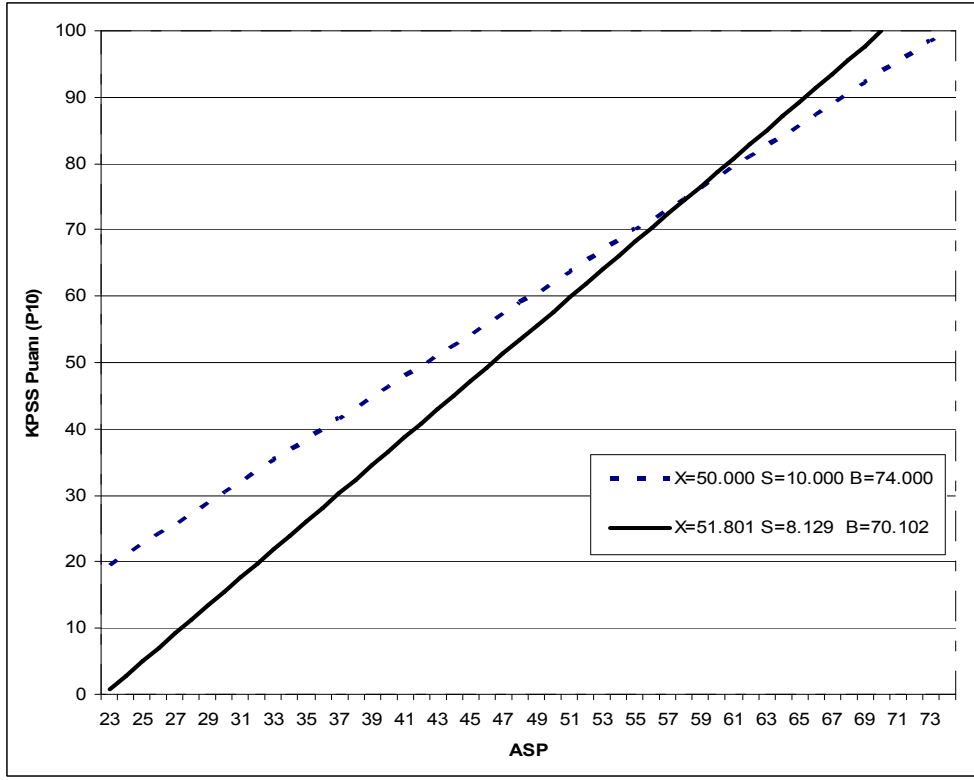

Şekil 4. KPSSP10 hesabında 3 parametrenin birden değişimiyle puanlarda meydana gelen değişim 
KPSS puanları hesaplanırken, yapılan dönüştürme işlemlerine rağmen, doğru olarak yanitlanan her sorunun, P10 puanına belirli miktarda ve hesaplanabilir bir katkısı vardır. Bu katkı her üç teste ilişkin dağılımın farklı olması nedeniyle testten teste değişiklik gösterir. GY ve GK testlerinden alınan $\mathrm{T}$ puanlarının 0.3; $\mathrm{EB}$ testinin $\mathrm{T}$ puanının ise 0.4 katsayısıyla çarpılması, P10 puanı içinde EB sorularının payının daha yüksek olduğunu düşündürebilir. Öngörülen pay \%40'tır. Geriye kalan \%60'1n \%30’u GY; $\% 30$ 'u GK puanlarından etkilenecektir. Ancak pratikte test puanlarının toplam puan içerisindeki payları bu şekilde gerçekleşmemektedir. Tablo 1'de, son 6 sınav için hesaplanan, her bir testteki 1 doğru artışının P10 puanında meydana getireceği artış miktarlarının yıllara göre dağılımı verilmiştir.

Tablo 1'de görüleceği gibi, 1 maddesi daha doğru yanıtlandığında test puanının en fazla artacağı test GY testidir. Bu durum son yapılan 6 sınav için de aynıdır. Testlerin ortalama katkılarına bakıldığında, 1 GY maddesinin .500 ; 1 GK maddesinin .453; 1 EB maddesinin ise .333 puan artış oluşturduğu görülmektedir. Bu durumun yıldan yıla değişiklik göstermesi ve bazı testlerin katkısının öngörülenden çok, bazılarının ise az olmasının nedeni, ASP bulmak için çarpılan katsayıların net sayılarıyla değil, T puanlarıyla çarpılmasıyla ilgilidir.

Tablo 1. Testlerdeki 1 doğru artışının KPSSP10'da meydana getireceği artıŞ miktarlarının yıllara göre değişimi

\begin{tabular}{lccccccc}
\hline Testler & \multirow{2006}{*2007}{} & $\mathbf{2 0 0 8}$ & $\mathbf{2 0 0 9}$ & $\mathbf{2 0 1 0}$ & $\mathbf{2 0 1 0}$ & \\
& & & & & Iptal & Tekrar & Ortalama \\
\hline GY & .460 & .537 & .466 & .477 & .457 & .603 & .500 \\
GK & .430 & .513 & .454 & .421 & .387 & .510 & .453 \\
EB & .317 & .350 & .348 & .297 & .307 & .374 & .333 \\
\hline
\end{tabular}

Adayların EB testinden bütün soruları doğru yanıtlamaları, GY ve GK testinden ise sıfir net yapmaları ve GK ve GK testinden 60'şar net yapıp sıfir EB neti birakmaları durumunda hesaplanacak olan P10 puanları Tablo 2'de sunulmuştur.

Tablo 2'den de görüleceği üzere, bir adayın sıfır GY ve GK neti varken EB testindeki maddelerin tamamını doğru yanıtlamış olsa bile alacağı puan 2010 yılı tekrar sınavı için 40.89 'dur. Son 6 sınavın ortalamasına bakıldığında bu puanın 45.53 olduğu görülmektedir. EB testinden sıfır neti olan bir adayın GY ve GK testlerinden 60'ar net yapması durumunda alacağ 1 puan ortalama 64.55 'tir. $\mathrm{Bu}$ puan diğer durum için hesaplanan puandan yaklaşı1k 20 puan yüksektir. 
Tablo 2. Değişik netlerle alınabilecek KPSSP10 puanlarının yıllara göre değişimi

\begin{tabular}{|c|c|c|c|c|c|c|c|c|c|}
\hline \multicolumn{3}{|c|}{ Net Sayıları } & \multicolumn{6}{|c|}{ SINAV YILI } & \multirow{2}{*}{ Ortalama } \\
\hline GY & GK & EB & 2006 & 2007 & 2008 & 2009 & $\begin{array}{c}2010 \\
\text { İptal }\end{array}$ & $\begin{array}{l}\text { 2010 } \\
\text { Tekrar }\end{array}$ & \\
\hline $\mathbf{0}$ & $\mathbf{0}$ & 120 & 47.85 & 38.49 & 46.56 & 49.56 & 49.82 & 40.89 & 45.53 \\
\hline 60 & 60 & 0 & 64.18 & 60.37 & 66.87 & 69.01 & 64.06 & 62.78 & 64.55 \\
\hline
\end{tabular}

\section{TARTIŞMA}

Araştırmanın bulguları, P10 hesaplarken kullanılan en yüksek ASP'nin düşük veya yüksek olmasının hesaplanan puanları etkilediğini ortaya koymaktadır. Geçerliliği iki yıl olan bir sınav için bu durumun eşitsizlik oluşturacağ1 açıktır. En yüksek puanlı kişinin gösterdiği performans, grup içerisinde aynı sırada olan kişilerin bir önceki veya bir sonraki yıl alınacak puana göre geride veya ileride olmasına neden olabilir. Örneğin son sınavda, ASP'si 52 olan, dolayısıyla sınava birlikte girdiği kişiler içerisinde ortada bulunan adayın puanı, en yüksek ASP'li adayın puanının 70 olmas1 durumunda 61.796; 74 olmas1 durumunda ise 63.607 olmaktadır. ASP'si 68 olup ortalamadan yaklaşık $2 \mathrm{~S}$ yüksek olan adayın puanı ise en yüksek ASP'nin 70 olmas1 durumunda 95.755; 74 olmas1 durumunda 90.074 olabilmektedir. Öğretmen adaylarının çok küçük puan farklarıyla sıralandığı ve atanıp atanmamada bazen 0.001 puanın bile önemli olduğu bu sınavda sadece sınava giren bir kişinin performansına bakarak 5 puanlık fark meydana getirmesinin eşitsizliğe neden olacağı açıktır.

Tekrar edilen EB sınavindaki en yüksek ASP iptal edilen sınavdakine göre düşüktür. En yüksek puan alanların bir kısmı tekrar edilen sınava girmemiş, diğerleri de iptal edilen sınavdaki kadar yüksek net elde edememişlerdir. $\mathrm{Bu}$ durumda, iki sınavda da benzer EB performansına sahip adaylardan ortalamadan 0.5 standart sapmadan daha fazla yüksek puan alan adayların P10 puanları yükselmiş; ortalamadan düşük veya 0.5 standart sapmadan daha az yüksek olan adayların ise düşmüştür. Bu durum iptal edilen sınavdakinden 10 net fazla yapıp, sıralamada 10 bin kişi ileri giden kişinin yükselmesi gereken standart puanının nasıl düşmüş olduğunu açıklayabilir.

ASP puan dağılımlarının ortalaması ve standart sapmasının, hesaplanan puanları etkilediği görülmektedir. Bir adayın grup içerisindeki sabit kalan sırası, düşük X ve düşük S'nin olduğu y1l yüksek; yüksek X ve S'nin olduğu yıl ise düşük puan etmektedir. GK ve GK testi puanlarının sadece EB testini alanlar için hesaplanması durumunda ASP puan dağılımı ortalaması 50; 
standart sapması 10 olacaktır ancak bu iki testin T puanları tüm KPSS Lisans adayları için hesaplandığından bu değerlerden farklı olabilmektedir. Böylelikle öğretmenlikle ilgisi olmayan kamu personeli adaylarının sınavda göstermiş olduğu başarı, o yıl sınava giren öğretmen adaylarının başarısını etkilemektedir. Üstelik de bu etki, öğretmen adaylarının başarısının diğerlerine göre daha düşük olması durumunda tüm puanların yüksek olması şeklinde ortaya çıkmaktadır. Yine aynı şekilde öğretmen adaylarının birbirlerine yakın puanlar alarak homojen bir grup oluşturmaları, puanlarının düşmesi sonucunu doğurmaktadır.

İptal nedeniyle yenilenen sinava girmeyen adayların GY ve GK netleri düşük olan, bu yüzden yenilenen EB testinde yüksek performans gösterseler dahi iyi bir puan alamayacağını düşünen kişiler olabileceği varsayılabilir. $\mathrm{Bu}$ durumda olan yaklaşık 40 bin adayın EB testi puanlarının olmaması nedeniyle ASP'lerinin hesaplanmamış olması, ASP ortalamasını yükseltmiş olabilir. Dağılımda uçta yer alan bir grubun çıkmış olması nedeniyle de standart sapma küçülmüş olabilir. ÖSYM tarafından açıklanan veriler bu tezi doğrulamaktadır. Yükselen $\mathrm{X}$, puanlarda düşmeye, düşen $\mathrm{S}$ ise artmaya neden olacaktır. B'nin düşmüş olmas1 70'in üzerinde yer alan P10 puanlarını yükseltirken, 70'in altındaki puanların düşmesi sonucunu getirecektir. Bu üç durumun bir arada yaşandığı düşünülürse, sınav puanının yanlış hesaplandığını düşünenlerin neden böyle bir sonuçla karşılaşmış olduklarına ilişkin daha tatminkâr bir açıklama yapmak mümkün gözükmektedir. Ancak bu açıklama yapılırken, neden puanların en yüksek puanlı bir kişiden ve EB sınavına girmemiş kamu personeli adaylarının test performanslarından etkilendiğine ilişkin yeni bir soruya da hazırlıklı olmak gerekmektedir.

Mevcut puan hesaplama yöntemi, her bir testin P10 içindeki payının öngörüldüğü gibi olmamasına neden olmaktadır. Son 6 sınavın incelenmesiyle ortaya çıkan bulgular, öğretmen adaylarının seçiminde kullanılan testler içerisinde en belirleyici olanının GY testi olduğu göstermektedir. Bu sinavla, sözel yeteneğin daha az gerektiği bir alanda öğrenim görmüş bir öğretmenden üst düzeyde sözel yetenek, sayısal yeteneğin daha az gerektiği bir alanda öğrenim görmüş öğretmenden de üst düzeyde sayısal yetenek sahibi olmaları beklenmektedir. Özel yetenek sınavlarıyla girilen bölümlerde (resim, müzik, beden eğitimi öğretmenliği vb.) öğrenim görmüş öğretmenler için hem sayısal hem de sözel yetenek bölümleri güçlük yaratıcı olabilmektedir. Atamalarda her branşın kendi içerisinde sıralanıyor olması nedeniyle bu durumun sorun oluşturmayacağı düşünülebilir ama ortaya çıkan durum böyle değildir. Her branştaki öğretmen adayının kendisiyle ilgili olan ve başarılı olacağı zaten beklenen bölümlerdeki tüm soruları doğru yanıtlamasının yanı sıra kendi alanıyla ilgili olmayan bölümün sorularını da yanıtlıor olması, atanabilmesi için şarttır. 
$\mathrm{Bu}$ sınavla MEB'in tarih sorularını yapabilen matematik öğretmeni; matematik sorularını yapabilen tarih öğretmeni atadığ 1 sonucu ortaya çıkmaktadır. Özel yetenek gerektiren müzik, resim, beden eğitimi öğretmenliği bölümünden mezun olmasına rağmen sayısal ve sözel yeteneği de yüksek olan adayların şansı çok daha yüksek olmaktadır.

\section{SONUÇ VE ÖNERILER}

Her y1l yapılan KPSS lisans sinavindan elde edilen P10 puanlarının geçerliliği 2 yıldır. Bu nedenle iki farklı yılda, farklı sorularla yapılmış ve farklı adayların girmiş olduğu iki sınavın puanlarının karşılaştırılabilir olabilmesi için azami özen gösterilmelidir. Mevcut puan hesaplama yöntemi bu anlamda eşitsizliklere yol açabilecek bir yapıdadır. Sınav sonuçları, P10 puanı hesaplanan tüm adayların performanslarının yanı sıra başka durumlardan da etkilenebilmekte, sinav birincisinin veya EB testini yanıtlamayan diğer kamu personeli adaylarının performanslarına göre yıldan yıla değişiklik gösterebilmektedir. Ayrıca, 3 farklı test yanıtlayan öğretmen adaylarının puanlarını en önemli olması gereken EB testi en az, GY testi ise en çok etkilemektedir. $\mathrm{Bu}$ problemlere çözüm olarak aşağıdaki öneriler geliştirilmiştir.

KPSS Lisans her yıl yapılan bir sınav olduğuna göre, yıllar arasında oluşabilecek eşitsizlikleri gidermek için geçerliliğinin 1 yıl olması sağlanmalıdır. P10 puanlarının hesaplanmasında en yüksek puanlı adayın puanını 100 puan olarak dönüştürmek için kullanılan formülden vazgeçilmelidir. P10 için ASP hesaplanırken, her 3 testi de yanıtlamış olan öğretmen adaylarının puanları dikkate alınmalı, hesaplamaya diğer kamu personeli adayları katılmamalıdır. Öğretmen atamalarında yasal zorunluluk nedeniyle GY ve GK puanlarından tamamen vazgeçilemiyorsa bile katsayıları düşürülerek EB testinin puan içindeki payı artırılmalıdır. ASP hesaplanmasındaki ağırlıklandırma işlemi $\mathrm{T}$ puanları üzerinde değil, net sayıları üzerinde yapılmalıdır. Her testten elde edilen netler ilgili katsayıla çarpıldıktan sonra hesaplanacak tek $Z$ puanı $T$ puanına çevrilmeli; elde edilecek puan atamaya esas teşkil edecek puan olmalıdır. 


\section{KAYNAKLAR}

Akyüz, Y. (2005). Türk Eğitim Tarihi. Ankara: Ankara Üniversitesi Eğitim Fakültesi Yayınları.

Crocker, L., \& Algina, J. (1986). Introduction to classical and modern test theory. San Diego, C.A: Harcourt Brace Jovanovich College Publisher.

Kan, A. (2010). Test Eşitleme: Aynı Davranışları Ölçen, Farklı Madde Formlarına Sahip Testlerin İstatistiksel Eşitliğinin Sınanması. Eğitimde ve Psikolojide Ölçme ve Değerlendirme Dergisi, 1(1), 16-21

MEB (2010). Milli Eğitim Temel Kanunu, [Online]: http://mevzuat.meb.gov.tr/html/88.html adresinden 19.12.2010 tarihinde indirilmiştir.

ÖSYM (2010 a). KPSS Lisans Kilavuzu, Ankara: ÖSYM.

ÖSYM (2010b). 17.09.2010 Tarihli Basın Duyurusu, [Online]: http://www.osym.gov.tr/belge/1-12135/2010-kpss-lisans-egitim-bilimleritestinin-iptali-17092-.html adresinden 19.12.2010 tarihinde indirilmiştir.

ÖSYM (2010c). 22.11.2010 Tarihli Basın Duyurusu, [Online]: http://www.osym.gov.tr/belge/1-12195/2010-kpss-lisans-egitim-bilimlerisinav-hakkinda-acikla-.html adresinden 24.11.2010 tarihinde indirilmiştir.

ÖSYM (2010d). 20.12.2010 Tarihli Basın Duyurusu, 2010 KPSS Lisans Eğitim Bilimleri Sınavi: KPSSP10 Puanının Hesaplanması, [Online]: http://www.osym.gov.tr/belge/1-12243/2010-kpss-lisans-egitim-bilimlerisinavi-kpssp10-puanin-.html adresinden 20.12.2010 tarihinde indirilmiştir.

Tekin, H. (1996). Ĕğitimde Ölçme ve Değerlendirme (9. Bask1). Ankara:Yarg1 Yayınları.

Turgut, M.F. ve Baykul, Y. (2010). Eğitimde Ölçme ve Değerlendirme. Ankara: Pegem Akademi. 